\title{
Integration of preoperative anatomic and metabolic physiologic imaging of newly diagnosed glioma
}

\author{
Susan M. Chang $\cdot$ Sarah Nelson $\cdot$ Scott Vandenberg $\cdot$ Soonmee Cha $\cdot$ \\ Michael Prados · Nicholas Butowski · Michael McDermott · Andrew T. Parsa • \\ Manish Aghi · Jennifer Clarke $\cdot$ Mitchel Berger
}

Received: 9 December 2008/ Accepted: 23 February 2009

(C) The Author(s) 2009. This article is published with open access at Springerlink.com

\begin{abstract}
Purpose To integrate standard anatomic magnetic resonance imaging in conjunction with uniformly acquired physiologic imaging biomarkers of untreated glioma with different histological grades with the goal of generating an algorithm that can be applied for patient management. Methods A total of 143 patients with previously untreated glioma were scanned immediately before surgical resection using conventional anatomical MR imaging, and with uniform acquisition of perfusionweighted imaging, diffusion-weighted imaging, and proton MR spectroscopic imaging. Regions of interest corresponding to anatomic and metabolic lesions were identified to assess tumor burden. MR parameters that had been found to be predictive of survival in patients with grade IV glioma were evaluated as a function of tumor grade and histological sub-type. Based on these finding both anatomic and physiologic imaging parameters were then integrated to generate an algorithm for management of patients with newly diagnosed presumed glioma. Results Histological analysis indicated that the population comprised 56 patients with grade II, 31 with grade III, and 56 with grade IV glioma. Based on standard anatomic imaging, the presence of hypointense necrotic regions in post-
\end{abstract}

S. M. Chang $(\bowtie) \cdot$ S. Vandenberg $\cdot$ S. Cha $\cdot$ M. Prados .

N. Butowski - M. McDermott - A. T. Parsa - M. Aghi .

J. Clarke - M. Berger

Department of Neurological Surgery, UCSF, 505 Parnassus Ave,

San Francisco, CA 94143, USA

e-mail: ChangS@neurosurg.ucsf.edu

S. Nelson $\cdot$ S. Cha

Department of Radiology and Biomedical Imaging, UCSF,

1700 4th Street, San Francisco, CA 94143, USA
Gadolinium T1-weighted images and the percentage of the $\mathrm{T} 2$ hyperintense lesion that was either enhancing or necrotic were effective in identifying patients with grade IV glioma. The individual parameters of diffusion and perfusion parameters were significantly different for patients with grade II astrocytoma versus oligodendroglioma sub-types. All tumors had regions with elevated choline to $\mathrm{N}$-acetylasparate index (CNI). Lactate was higher for grade III and grade IV glioma and lipid was significantly elevated for grade IV glioma. These results were integrated into a proposed management algorithm for newly diagnosed glioma that will need to be prospectively tested in future studies. Conclusion Metabolic and physiologic imaging characteristics provide information about tumor heterogeneity that may be important for assisting the surgeon to ensure acquisition of representative histology. Correlation of these integrated MR parameters with clinical features will need to be assessed with respect to their role in predicting outcome and stratifying patients into risk groups for clinical trials. Future studies will use image directed tissue sampling to confirm the biological interpretation of these parameters and to assess how they change in response to therapy.

Keywords Newly diagnosed glioma - MRSI · DWI · PWI

\section{Introduction}

Gliomas are spatially heterogeneous lesions and the accuracy of histological diagnosis depends upon obtaining a representative tissue sample [1]. This is especially relevant for non-enhancing lesions for which a biopsy rather than an 
extensive resection may be indicated because of the location of the mass, or for those that are concerning for a mixture of grades on standard imaging. In addition, lesions with the same grade and similar appearance on conventional anatomic imaging may have variable clinical outcomes [2-5]. The availability of non-invasive biomarkers that could be used to direct tissue sampling to an appropriate location, to stratify patients into groups that are likely to respond to the specific mechanism of action of therapy or to provide an early assessment of whether a treatment is being effective would be extremely valuable for directing patient care.

Standard MRI depicts areas of contrast enhancement on T1 weighted images as well as abnormalities related to nonenhancing tumor and cerebral edema on T2 weighted images $[6,7]$. While these images are widely used for diagnosis of tumor versus other mass lesions and for assessment of response to therapy, there is a growing realization that there are circumstances where they can be misleading or ambiguous [8-10]. This is especially true for evaluating new therapeutic agents which focus on anti-angiogenic activity and inhibiting signalling pathways rather than on directly causing cytotoxic effects.

Metabolic and physiological MR imaging techniques such as perfusion-weighted imaging (PWI), diffusion weighted imaging (DWI), and MR spectroscopic imaging (MRSI) are increasingly being used in clinical and research studies to identify regions with biological characteristics that reflect malignant behaviour and to evaluate treatment effects. PWI measures hemodynamic properties such as tissue blood volume and vessel permeability [11-16]. DWI gives information about the apparent diffusion coefficient (ADC) of water and provides an opportunity to examine differences in cell density and tissue structure [17-23]. Proton MR spectroscopic imaging (MRSI) provides estimates of the levels of cellular metabolites that may be relevant for evaluating the aggressiveness of tumors and for defining tumor burden [24-33]. Previous studies consisted of limited numbers of patients with variable acquisition methodology thereby restricting comparisons across different grades of tumors.

The objective of this study was to integrate uniformly acquired, non-invasive MR imaging parameters derived from PWI, DWI, and MRSI with standard anatomic imaging of a large number of untreated glioma and to generate a practical algorithm for patient management. The parameters that were considered had been identified from a previous analysis of the sub-population with grade IV glioma as being predictive of poor survival [34] and were expected to be valuable as biomarkers of malignant behaviour. The long-term goal of this research is to apply this proposed algorithm prospectively and to correlate these integrated MR parameters with clinical features to assess their role in predicting outcome and stratifying patients into risk groups for clinical trials.

\section{Methods}

One hundred and forty three treatment-naïve adults who were subsequently diagnosed as having supratentorial glioma received an MR imaging examination 1 day prior to image-guided surgery. Patients gave informed consent for acquisition of the imaging studies based upon a protocol approved by our institutional research board. Standard anatomic images were acquired as needed for clinical care and included T2-weighted fast spin echo images and postGadolinium T1-weighted images. When possible within the time limitations imposed by this pre-surgery examination, patients also received PWI, DWI, and MRSI. Histological diagnosis of glioma was based upon the WHO II classification of tissue obtained at the time of surgical resection. Differences between MR parameters were assessed for variations with tumor grade and histological sub-types. Survival data had been collected and reviewed for the cohort with grade IV glioma in order to identify which MR parameters were likely to be of interest.

\section{MR examination}

Patients were imaged using a Signa Echospeed 1.5T scanner (General Electric Healthcare, Milwaukee, WI, USA) with a commercially available quadrature head coil. The imaging protocol for patients with suspected glioma in our institution includes a T1-weighted three-plane scout ( TR/TE $=400 / 12 \mathrm{~ms}$ ); pre- and post-contrast T1-weighted $3 \mathrm{D}$ spoiled gradient echo $(\mathrm{SPGR}-\mathrm{TR} / \mathrm{TE}=32 / 8 \mathrm{~ms}, 40$ flip angle, $180 \times 240 \mathrm{~mm}^{2} \mathrm{FOV}$, with $192 \times 256$ matrix, 124 slices and 1-1.5 mm slice thickness); T2-weighted fluid attenuated inversion recovery images (FLAIR - TR/ $\mathrm{TE} / \mathrm{TI}=10000 / 143 / 2200 \mathrm{~ms}, 220 \times 220 \mathrm{~mm}^{3}$ FOV, with $256 \times 256$ matrix, 32-48 slices with 3-5 mm thickness); T2-weighted fast spin echo (FSE - TR/TE $=3000 / 105 \mathrm{~ms}$, $260 \times 260 \mathrm{~mm}^{2}$ FOV, with $256 \times 256$ matrix, 120 slices with $1-1.5 \mathrm{~mm}$ thickness).

Anatomic images were aligned to the post-Gd SPGR images using software developed in our research group $[35,36]$. Tumor region-of-interest segmentation was performed using a semi-automated segmentation software package [3, 7, 33]. Contrast-enhancing (CE) and necrotic (NEC) regions were contoured on the post-Gd SPGR images. The T2-hyperintense region (T2L) was contoured on FSE or FLAIR images. The NE lesion was defined as the T2 lesion minus the $\mathrm{CE}$ and NEC components. Normalappearing white matter (NAWM) regions were automatically segmented using the FSL software package [37]. 
Perfusion-weighted imaging

Bolus-tracking perfusion images were acquired following a bolus of $0.1 \mathrm{mmol} / \mathrm{Kg}$ body weight Gd-DTPA that was injected into the antecubital vein at a rate of $5 \mathrm{ml} / \mathrm{s}$. Dynamic susceptibility contrast echoplanar gradient echo images were acquired before, during and after the passage of the contrast agent. Perfusion-weighted imaging parameters were $(\mathrm{TR} / \mathrm{TE}=1700 / 100 \mathrm{~ms}$, matrix $=256 \times 256$, $7-9$ slices, FOV $=400 \times 400 \mathrm{~mm}^{2}$, slice thickness $3-5 \mathrm{~m}$, with a total of 60 time points. Perfusion datasets were processed to yield non-parametric estimates of percent $\Delta \mathrm{R} 2 *$ recovery (\% REC), and $\Delta \mathrm{R} 2 *$ peak heights $(\mathrm{PH})$ using in-house software [38, 39]. Maps of these parameters were rigidly aligned to the post contrast $\mathrm{T} 1$-weighted images using VTK software and then re-sampled to the same spatial resolution [40].

\section{Diffusion weighted imaging}

Acquisition parameters were $\mathrm{TR} / \mathrm{TE}=10000 / 100 \mathrm{~ms}$, matrix $128 \times 128$, FOV $=360 \times 360 \mathrm{~mm}^{2}$ with $38-36$ slices and 3-5 mm slice thickness, b value $1000 \mathrm{~s} / \mathrm{mm}^{2}$, gradient strength $=0.04 \mathrm{~T} / \mathrm{m}$, gradient duration $=21 \mathrm{~ms}$, and gradient separation $=27 \mathrm{~ms}$. The diffusion-weighted images were processed to yield apparent diffusion coefficient (ADC) maps using in-house software [41]. The maps were rigidly aligned to the post-contrast $\mathrm{T} 1$ weighted images using the VTK software package and then re-sampled to the same spatial resolution as the anatomic images [40].

\section{H MRSI data}

MR spectroscopic imaging data were acquired using PRESS volume selection, 3-D phase encoding and VSS outer volume suppression bands that were developed in our laboratory [42]. The selected volume was prescribed on the post-contrast T1-weighted image to cover as much of the lesion as possible and to include normal-appearing tissue from the contralateral hemisphere. The acquisition employed a $12 \times 12 \times 8$ phase encoding matrix with reduced sampling to cover only the central elliptical region of k-space and with field of view $120 \times 120 \times 80 \mathrm{~mm} \quad(\mathrm{TR} / \mathrm{TE}=1000 /$ $144 \mathrm{~ms}$ ). In the majority of cases the sequence employed a spectral editing scheme that required two separate acquisitions and was able to distinguish between resonances corresponding to lactate and lipid [43]. The spectroscopic data were processed using in-house software that has been described previously [35]. Parameters that are estimated include peak locations, heights, areas, and linewidths for each voxel. For the lactate-edited data, summed acquisitions gave spectra with choline, creatine, NAA, and lipid, while the subtracted data gave lactate alone.
The choline-to-NAA index (CNI) was estimated as described previously based upon the differences in relative peak heights between tumor and normal tissue [44]. The relationship between metabolite levels and anatomic regions was analyzed by resampling masks from the regions of interest to match the resolution of the spectral data. Voxels that were predominantly in NAWM, the NE lesion, the CE Lesion or the NEC lesion, as well as voxels that had CNI values greater than 2 or 3 were used to calculate the statistics for the analysis. The registration error between the MRSI data and anatomic images was assumed to be negligible because they were acquired immediately following the post-contrast SPGR images.

\section{Analysis of MR parameters}

Volumes and the variations intensity of individual MR parameters were recorded within the regions of interest corresponding to the T2 lesion, NE lesion, CE lesion, NEC lesion, and NAWM. To facilitate comparison of parameter values between patients, the values of $\mathrm{ADC}, \mathrm{PH}$, choline, creatine, and NAA were normalized to their median values within NAWM. Lactate and lipid maps were normalized to the median value of NAA within NAWM. Measures of the spatial extent of regions with abnormal DWI parameters were determined by considering the volume within the T2 lesion that had normalized ADC less than 1.5, vol (nADC < 1.5). Measures of the spatial extent of the metabolic lesions were obtained by considering the number of voxels with $\mathrm{CNI}$ values greater than $2, \mathrm{v}(\mathrm{CNI}>2)$, or the number of voxels with $\mathrm{CNI}$ greater than $3, \mathrm{v}(\mathrm{CNI}>3)$. The sum of the normalized lactate and lipid values within the metabolic lesions corresponding to $\mathrm{CNI}>2$, sum(Lac/ nNAA) and sum(Lip/nNAA) formed the basis for analysis of differences between tumor grade.

\section{Statistical analysis}

The previous analysis of the cohort with grade IV glioma had generated Kaplan-Meier survival curves and applied Cox proportional hazards model to evaluate the influence of a range of different parameters on survival. The $\%$ CEL + NEC, vol (nADC < 1.5), v(CNI >2), sum(Lac/ nNAA), and sum(Lip/nNAA) were identified as being significant in that analysis and were therefore used in this study to make comparisons between grades. Other parameters that were examined on an exploratory basis to assess differences between tumor grades included the median and extreme values of the various MR parameters in the anatomic and metabolic regions of interest. Differences between populations were analyzed using the Wilcoxon rank sum test, with a $P$ value of 0.05 being used as a cut-off for significance. 


\section{Results}

A total of 143 patients with untreated glioma were included in the study. The distribution of histological diagnosis of grade and sub-type is summarized in Table 1 . The range of visual appearance of these lesions on T2 and post-Gadolinium T1-weighted images are illustrated in Fig. 1. As can be seen in these examples, the majority of the grade II gliomas were non-enhancing, while the grade III gliomas had either no or relatively small enhancing volumes and the grade IV gliomas typically had both enhancing and necrotic components. The results of the individual parameters are presented below.

\section{Variations in anatomic volumes}

The median and ranges of anatomic volumes are summarized in Table 2. The size of the overall $\mathrm{T} 2$ lesion was highly variable, with median values that were similar for grade II and III, but larger for grade IV glioma. Some of the patients with grade IV glioma had sub-regions that were relatively bright and could be attributed to edema. Six of the patients with grade III and 4 of the patients with grade

Table 1 Summary of the patient population based upon tumor grade and histology

\begin{tabular}{llrrr}
\hline Grade & AC & OA & OD & Total \\
\hline II & 18 & 14 & 24 & 56 \\
III & 18 & 10 & 3 & 31 \\
IV & 56 & - & - & 56 \\
\hline
\end{tabular}

$O D$ oligodendroglioma, $O A$ oligoastrocytoma, $A C$ astrocytoma
II glioma had cystic regions that were identified as being hyperintense on the FSE images but were hypointense, with a relatively well defined border on both the FLAIR and T1-weighted images. These regions were excluded from the analysis of metabolic and physiological parameter values. The median volumes of the NE lesions were similar between different tumor grades.

Fifteen of the grade III gliomas were non-enhancing and the other 16 had volumes of $\mathrm{CE}$ that ranged from 0.2 to $17.3 \mathrm{cc}$ (see Table 2). Although it is not possible to make statistical inferences due to the small number of patients that had this histological sub-type, it was noted that all three of the ODIII were enhancing and that their CE lesions had volumes of $1.3,2.2$, and $17.3 \mathrm{cc}$. There were $55 / 56$ patients with grade IV glioma who had regions of enhancement and $49 / 56$ who had regions of visually identifiable necrosis. The volumes of both the CE and NEC lesions were highly variable (see Table 2), with medians of $15.2 \mathrm{cc}$ and $4.5 \mathrm{cc}$, respectively. If the presence of necrosis was used to distinguish between grade IV and grade II/grade III glioma then $136 / 143$ (95\%) of the lesions would be correctly classified and only seven of the grade IV gliomas would be wrongly classified.

Percentage volume of enhancement and necrosis in the $\mathrm{T} 2$ lesion

In the previous analysis it had been determined that while the absolute pre-surgery lesion volumes were not associated with survival for the patients with grade IV glioma, the sum of the volumes of CE and NEC lesion as a percentage of the entire T2 lesion (\% CEL + NEC) was a

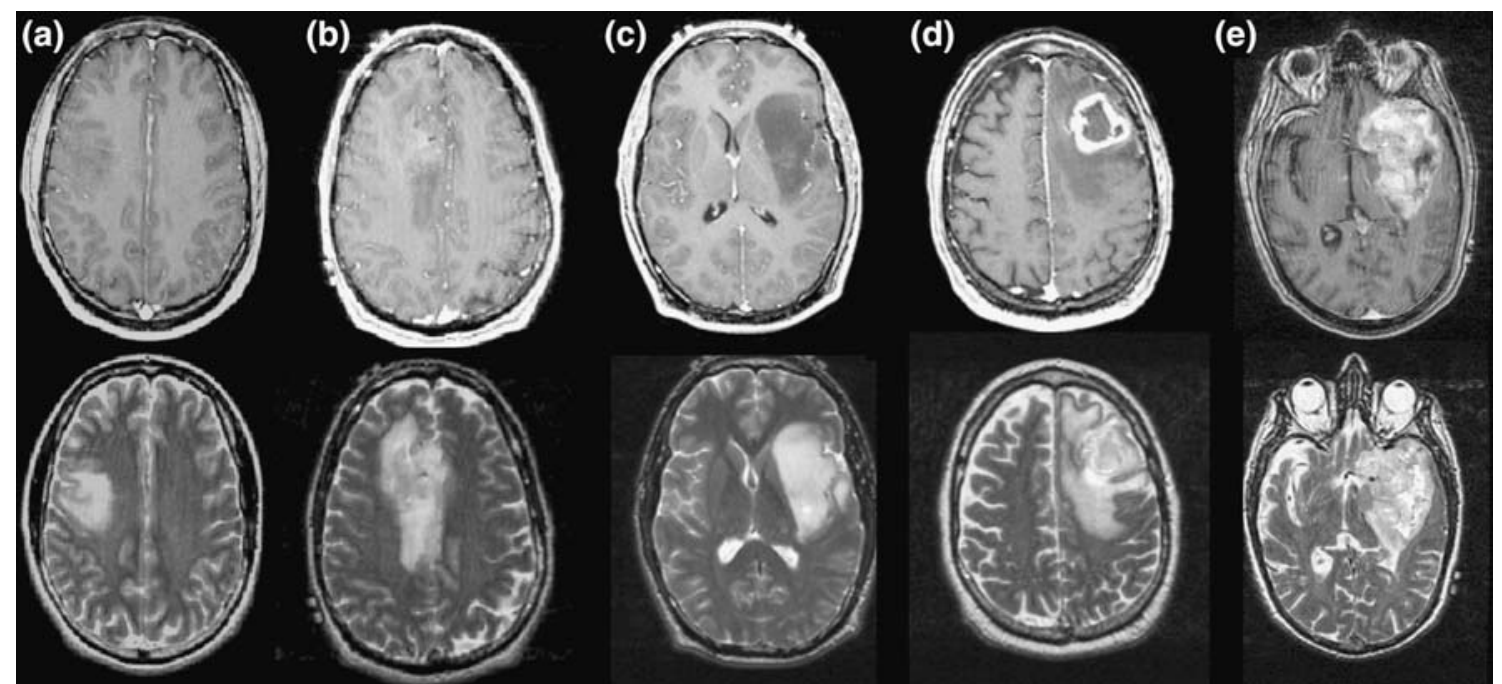

Fig. 1 T1-weighted post-Gadolinium and T2-weighted images of Grade II (a, b), III (c) and IV (d, e) glioma. The volumes of the overall T2 hyperintensity are large in all three cases, but the T1-weighted images shows larger contrast enhancement and/or hypointense necrotic regions for the grade IV glioma, no enhancement for the grade II lesion and marginal or no enhancement for the grade III gliomas 
Table 2 Differences in median volume of the T2 hyperintensity (T2L), contrast enhancing (CE) lesion, and necrotic (NEC) lesion for tumors of various grades

\begin{tabular}{|c|c|c|c|c|c|c|}
\hline Grade & Value & $\begin{array}{l}\text { T2 lesion } \\
\text { volume (cc) }\end{array}$ & $\begin{array}{l}\text { NE lesion } \\
\text { volume (cc) }\end{array}$ & $\begin{array}{l}\text { CE lesion } \\
\text { volume (cc) }\end{array}$ & $\begin{array}{l}\text { NEC lesion } \\
\text { volume (cc) }\end{array}$ & $\begin{array}{l}\%(\mathrm{CEL}+\mathrm{NEC}) \\
\text { of } \mathrm{T} 2 \text { lesion }\end{array}$ \\
\hline \multirow[t]{3}{*}{ II } & Median & 42.3 & 38.3 & 0.5 & - & 0.0 \\
\hline & Range & $0.6-257.2$ & $0.6-252.2$ & $0.2-5.8$ & - & $0.0-9.5$ \\
\hline & $N$ & 56 & 56 & 6 & 0 & 56 \\
\hline \multirow[t]{3}{*}{ III } & Median & 39.9 & 38.8 & 0.9 & - & 0.6 \\
\hline & Range & $6.9-139.8$ & $5.9-139.8$ & $0.2-17.3$ & - & $0.0-32.7$ \\
\hline & $N$ & 31 & 31 & 16 & 0 & 31 \\
\hline \multirow[t]{3}{*}{ IV } & Median & 60.3 & 43.2 & 15.2 & 4.5 & 34.1 \\
\hline & Range & $12.1-166.9$ & $4.5-123.4$ & $0.3-93.3$ & $0.0-34.5$ & $0.0-92.9$ \\
\hline & $N$ & 56 & 56 & 55 & 49 & 56 \\
\hline
\end{tabular}

Note that if the presence of necrosis were used as criteria for predicting grade then 49/56 grade IV lesions would be correctly distinguished from the grade II and grade III lesions

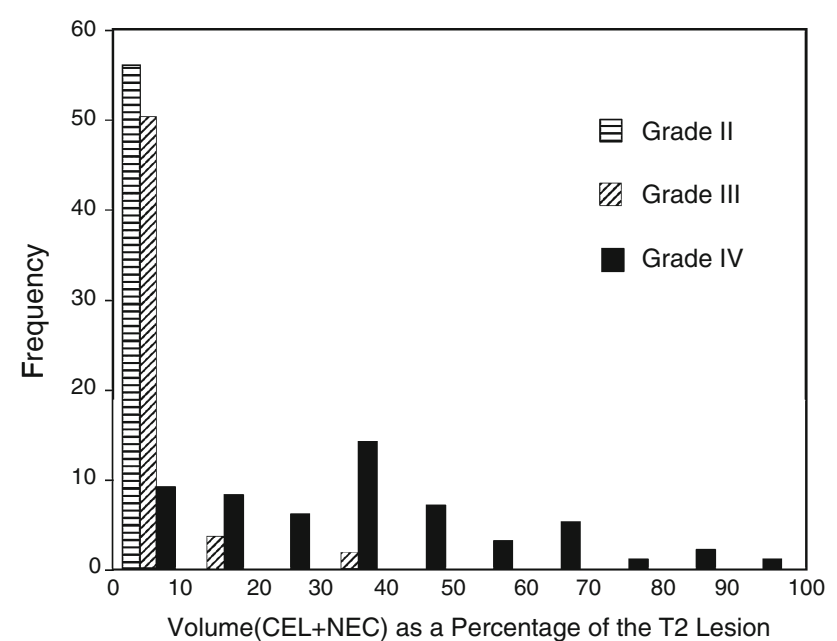

Fig. 2 Frequency distribution of the parameter $\%($ CEL + NEC $)$ versus tumor grade. Note that the vertical scale has been modified for the grade III lesions by a factor of $56 / 31$ to facilitate direct comparisons between grades

predictor of poor survival. Figure 2 shows the histogram of these percentages for lesions of all three grades. If this metric was used to distinguish grade IV from grade III and grade II glioma with a cut-off of $10 \%$ then $131 / 143(92 \%)$ of the lesions would be correctly classified with $9 / 56$ grade IV and $3 / 31$ grade III glioma being placed in the wrong category.

Volume of the T2 lesion with low ADC values

As is seen in Table 3, the levels of ADC within the lesions are typically higher than the values in NAWM. The cut-off of 1.5 times the median value in NAWM had been determined from previous studies [45]. Although there was considerable variability, the vol (nADC $>1.5)$ increased with grade, and the value for grade IV glioma (median
$30.1 \mathrm{cc}$ ) was significantly higher than for the other grades. This was true for the absolute volume as well as for the volume as a percentage of the T2 lesion. The nADC in ACII (median 1.93) and OAII (median 1.81) was significantly higher than for the ODII (median 1.54) and for high grade gliomas (medians 1.55 and 1.54). The substantial differences in nADC between ACII and ODII sub-types may be useful in generating a visual representation of probable oligo- and astro-regions of non-enhancing tumor. Figure 3 gives an example of this colorful display for NAWM (green), ODII (pink), ACII (blue) and OAII. Note that the OAII, which is a lesion with mixed characteristics, has heterogeneous areas of nADC that correspond in color intensity to both of the other two sub-types.

Comparisons between the $\mathrm{nADC}$ values in the CE lesion were only feasible for the grade III and grade IV gliomas, and the differences between them were not significant. From inspection of the images, it was clear that some regions of the NE lesion had nADC less than 1.5, but that other regions had much higher nADC. Of interest in comparing the diffusion and metabolic parameters is that the nADC values at voxels with maximum CNI were similar to the median values in the NE lesion and showed the same significant differences for the ACII and OAII sub-types.

Differences in perfusion values between sub-populations

Although perfusion values were not found to be predictive of survival in our previous analysis, the presence of abnormal vasculature is used as a hallmark of grade IV gliomas for histological evaluation. We therefore performed a comparison between the values in different grades for our patient population. It should be noted that the nPH parameter shown in Table 4 has been shown to correlate 
Table 3 Volumes with low ADC and the ADC values in various regions

\begin{tabular}{|c|c|c|c|c|}
\hline Grade & Vol $(\mathrm{ADC}<1.5)$ within $\mathrm{T} 2 \mathrm{~L}$ & Value in NE lesion & Value in CE lesion & Value at CNImax \\
\hline ACII & $5.2 \mathrm{cc}$ & $1.93 *$ & 1.37 & $2.08 *$ \\
\hline$N=18 / 1$ & $\mathrm{sd}=9.0$ & $\mathrm{sd}=0.42$ & - & $\mathrm{sd}=0.44$ \\
\hline OAII & $9.3 \mathrm{cc}$ & $1.81 *$ & 1.65 & $1.81 *$ \\
\hline$N=14 / 2$ & $\mathrm{sd}=8.1$ & $\mathrm{sd}=0.19$ & - & $\mathrm{sd}=0.43$ \\
\hline ODII & $10.1 \mathrm{cc}$ & 1.54 & 1.50 & 1.61 \\
\hline$N=23 / 3$ & $\mathrm{sd}=33.4$ & $\mathrm{sd}=0.20$ & - & $\mathrm{sd}=0.42$ \\
\hline III & $14.1 \mathrm{cc}$ & 1.55 & 1.38 & 1.61 \\
\hline$N=27 / 13$ & $\mathrm{sd}=20.3$ & $\mathrm{sd}=0.35$ & $\mathrm{sd}=0.33$ & $\mathrm{sd}=0.60$ \\
\hline IV & $30.1 \mathrm{cc}^{*}$ & 1.47 & 1.42 & 1.48 \\
\hline$N=46 / 46$ & $\mathrm{sd}=16.2$ & $\mathrm{sd}=0.28$ & $\mathrm{sd}=0.25$ & $\mathrm{sd}=0.35$ \\
\hline
\end{tabular}

The values in the sub-populations marked with an asterisk were significantly different than the values in the other $(P<0.05)$

Fig. 3 A comparison of the distributions and different ranges of ADC values for subtypes of grade II glioma. The green area represents ADC values characteristic of normal appearing white matter, the pink regions ADC values that are characteristic of

oligiodendroglioma (a) and the blue values are characteristic of astrocytoma (b). Note that the mixed subtype oligoastocytoma (c) has a mixture of pink and blue regions

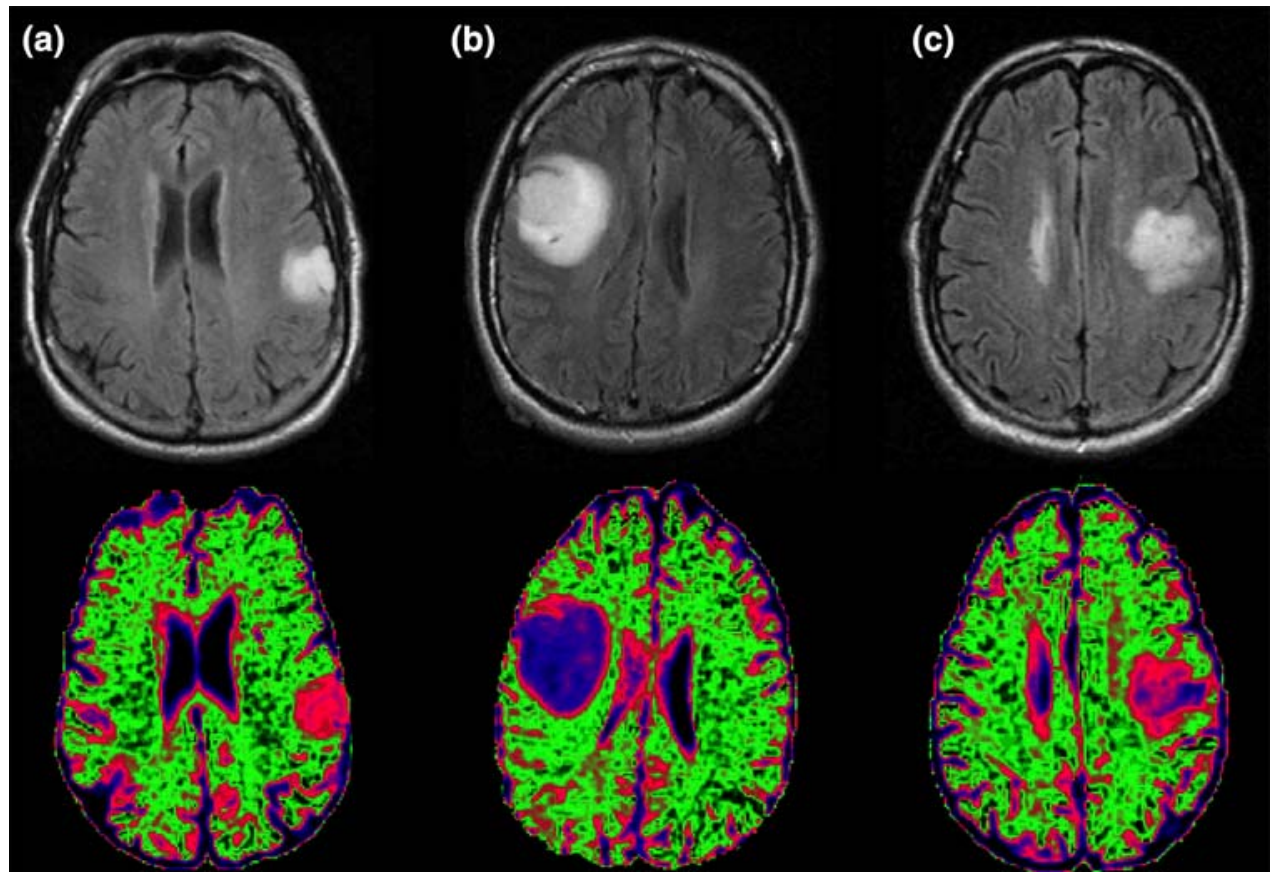

directly with other MR measures of cerebral blood volume [38]. Also, as is seen in the example data in Figs. 4, 5, 6, 7, 8,9 , and 10 , the values of these parameters in normal appearing gray matter (NAGM) are approximately twice the values in NAWM. This means that distinguishing tumor from normal anatomy often requires visual comparison of the $\mathrm{nPH}$ maps to the T1 or T2 weighted images. From the evaluation of median and 75 th percentile values of $\mathrm{nPH}$ it appears that regions with values elevated above NAWM or NAGM were, as expected, primarily in regions of enhancement. The 75th percentile of these values was higher in grade IV relative to grade III gliomas. For the ODII, grade III, and grade IV gliomas, the 75th percentile of the $\mathrm{nPH}$ in the NE lesion was significantly higher than for the ACII and OAII. The finding of elevated perfusion characteristics in grade II oligodendroglioma has been described previously [14, 15] and suggests that there were some regions of the NE lesion that had increased vasculature but that this had not yet become leaky enough to be detected as regions of $\mathrm{CE}$. In addition, it means that as a single parameter alone, perfusion imaging cannot distinguish the grade of tumor. Although the values are not shown in Table 4, it was observed that only regions of $\mathrm{CE}$ had significant differences in signal recovery $(\% \mathrm{Rec})$ from the values in NAWM.

\section{Number of voxels with elevated CNI}

The number of voxels with CNI $>2$ and CNI $>3$ for different tumor grades are reported in Table 5. While there 
Table 4 Summary of perfusion parameters versus tumor grade and subtype

\begin{tabular}{lllll}
\hline Grade & Median nPH in NE lesion & $75 \% \mathrm{nPH}$ in NE lesion & Median nPH in CE lesion & $75 \% \mathrm{nPH}$ in CE lesion \\
\hline ACII & 0.87 & 1.19 & 0.53 & 1.19 \\
$N=15 / 1$ & $0.47-1.26$ & $0.68-1.95$ & - & - \\
OAII & 0.95 & 1.25 & 1.74 & 2.06 \\
$N=13 / 1$ & $0.59-1.37$ & $0.91-2.08$ & - & - \\
ODII & 1.24 & $1.57^{*}$ & 1.39 & 1.57 \\
$N=21 / 3$ & $0.83-2.27$ & $0.55-2.49$ & $1.32-2.03$ & $1.55-2.49$ \\
III & 1.20 & $1.63^{*}$ & 1.21 & 1.46 \\
$N=22 / 10$ & $0.49-1.89$ & $0.77-3.07$ & $0.91-4.60$ & $1.05-4.96$ \\
IV & 0.96 & $1.61 *$ & 1.68 & $2.60 *$ \\
$N=49 / 46$ & $0.20-2.16$ & $0.61-3.02$ & $0.79-5.20$ & $1.03-6.55$ \\
\hline
\end{tabular}

The $\mathrm{nPH}$ values were normalized using the intensities from normal appearing white matter. Note that the median nPH values in normal gray matter are approximately 2.0 and that the median of the $75 \% \mathrm{nPH}$ values in normal appearing white matter were 1.34 (range 1.22-1.58), 1.32 (range 1.20-1.53), and 1.42 (range 1.15-1.68) for patients with grade II, III and IV lesions, respectively

Values in the subpopulations marked with an asterisk were significantly different from the values in the other $(P<0.05)$
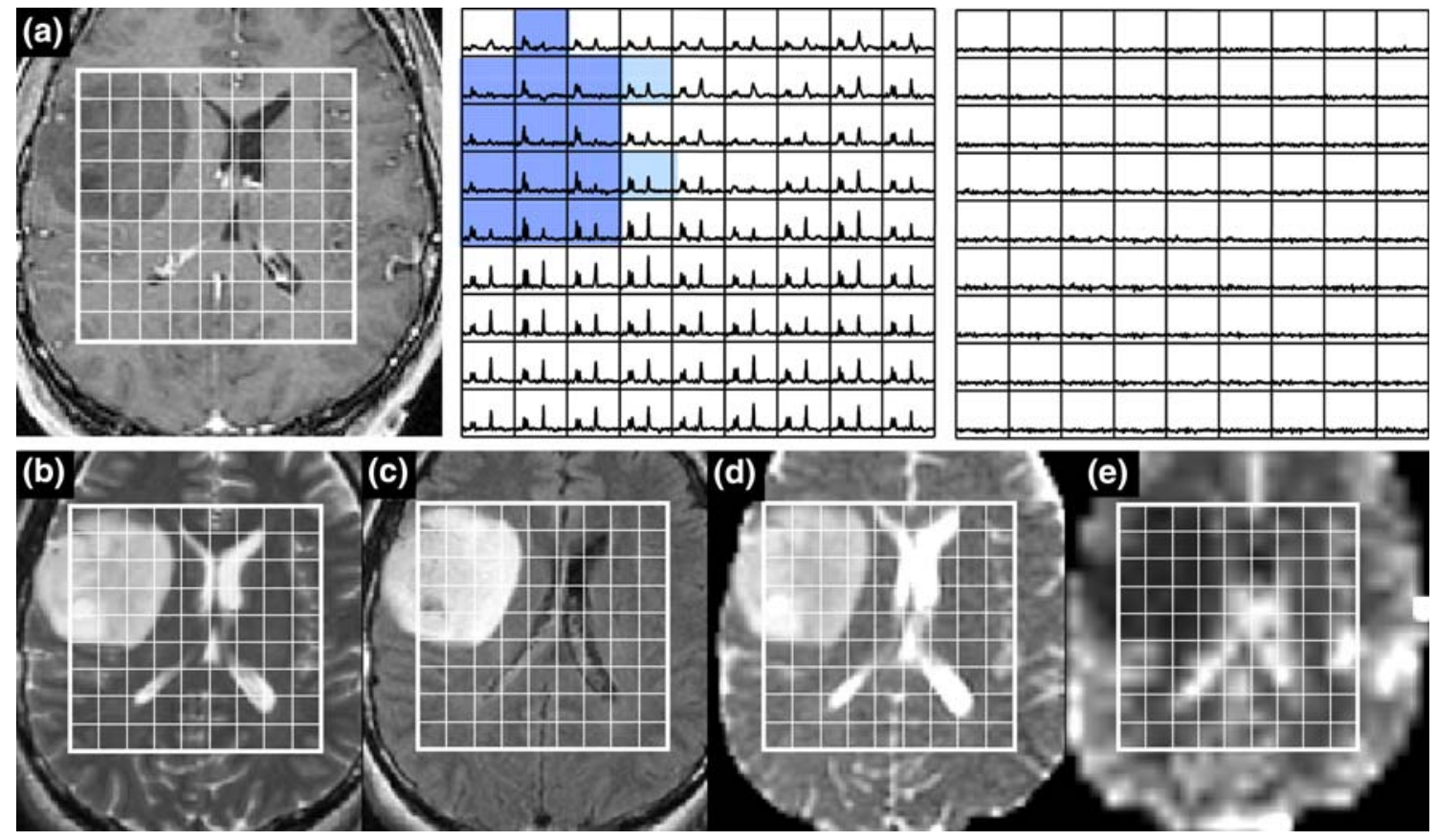

Fig. 4 Patient with an ACII: a is a post-Gadolinium T1-weighted image, $\mathbf{b}$ is a FSE image, $\mathbf{c}$ is a FLAIR image, $\mathbf{d}$ is an ADC map, and $\mathbf{e}$ is a map of $\mathrm{nPH}$. The lactate edited spectra correspond to the sum

was a trend for the metabolic lesions to get larger with grade, there was considerable variability between subjects, and even the grade II gliomas had substantial abnormalities. Another factor of interest is that although the median and maximum CNI did not change substantially between grades, there was a larger range in values for the ODII, grade III and grade IV gliomas. In addition, the ratio of the number of voxels with elevated CNI to the total number of voxels in the T2 lesion that were covered by the PRESS selected volume was highest in the ODII lesion (median (choline, creatine, NAA, and lipid if it is present) and the difference (which would show lactate if present). Light blue voxels show $2<\mathrm{CNI}<3$ and dark blue voxels show $\mathrm{CNI}>3$

0.97) and lower in the ACII and OAII lesions (median 0.55 and 0.47 , respectively).

Figures 4 and 5 show summary data from patients with ACII. The voxels with CNI between two and three are highlighted in light blue and those with CNI $>3$ in designated by a darker blue color. There were no voxels with significant lactate or lipid in these patients. The CNI2 volume was 53 voxels for the patient in Fig. 4 and 42 for the patient in Fig. 5. The maximum CNI values were 8.2 and 5.7, respectively. In both cases there was no CE, the 

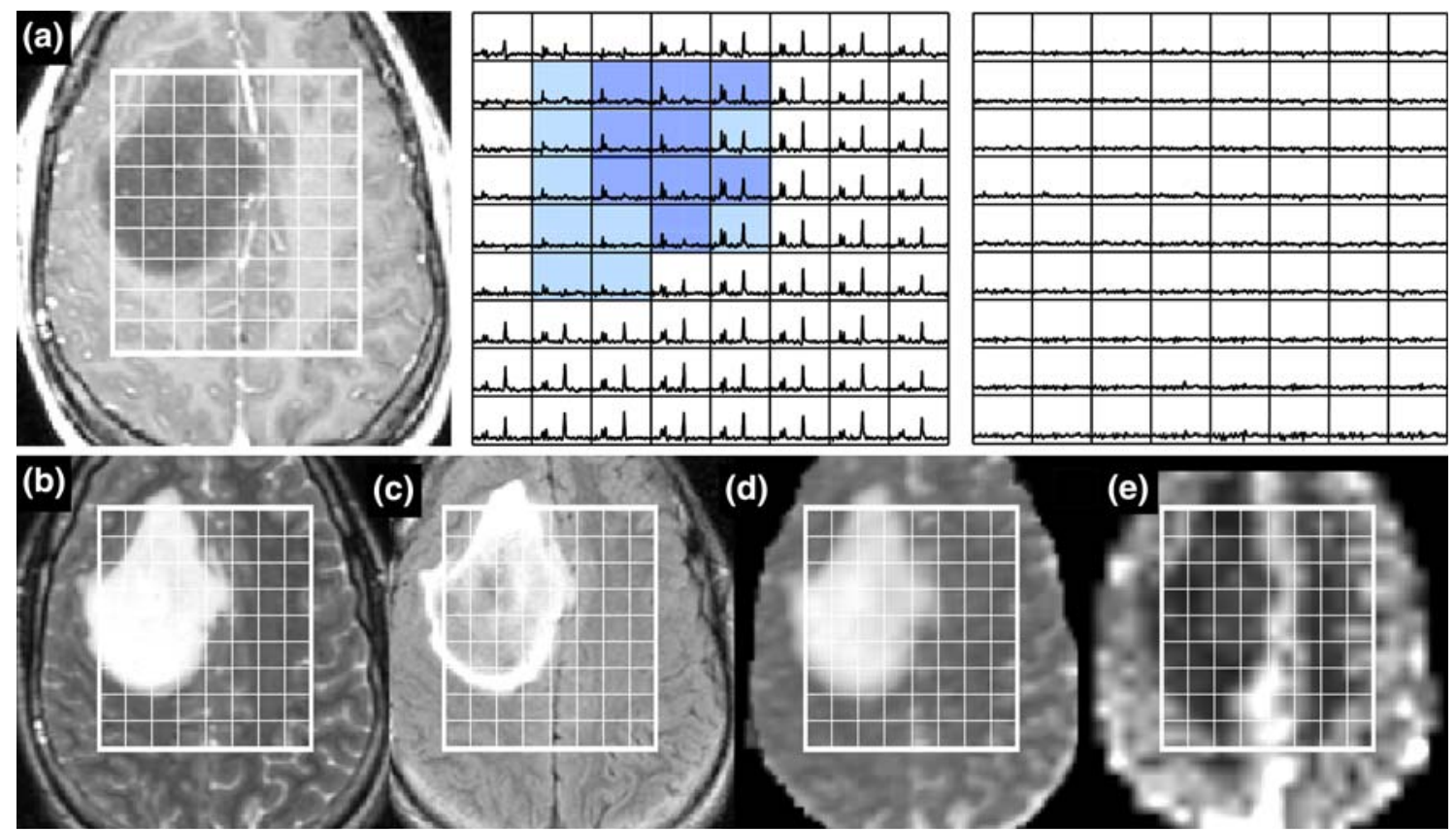

(d)
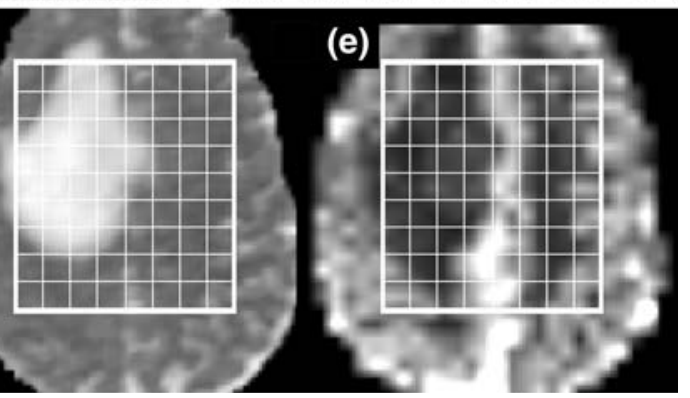

Fig. 5 Patient with an ACII: a is a post-Gadolinium T1-weighted image, $\mathbf{b}$ is a FSE image, $\mathbf{c}$ is a FLAIR image, $\mathbf{d}$ is an ADC map, and $\mathbf{e}$ is a map of $\mathrm{nPH}$. The lactate edited spectra correspond to the sum (choline, creatine, NAA, and lipid if it is present) and the difference

(which would show lactate if present). Light blue voxels show $2<\mathrm{CNI}<3$ and dark blue voxels show $\mathrm{CNI}>3$. Note the low $\mathrm{nPH}$ and high relatively uniform nADC
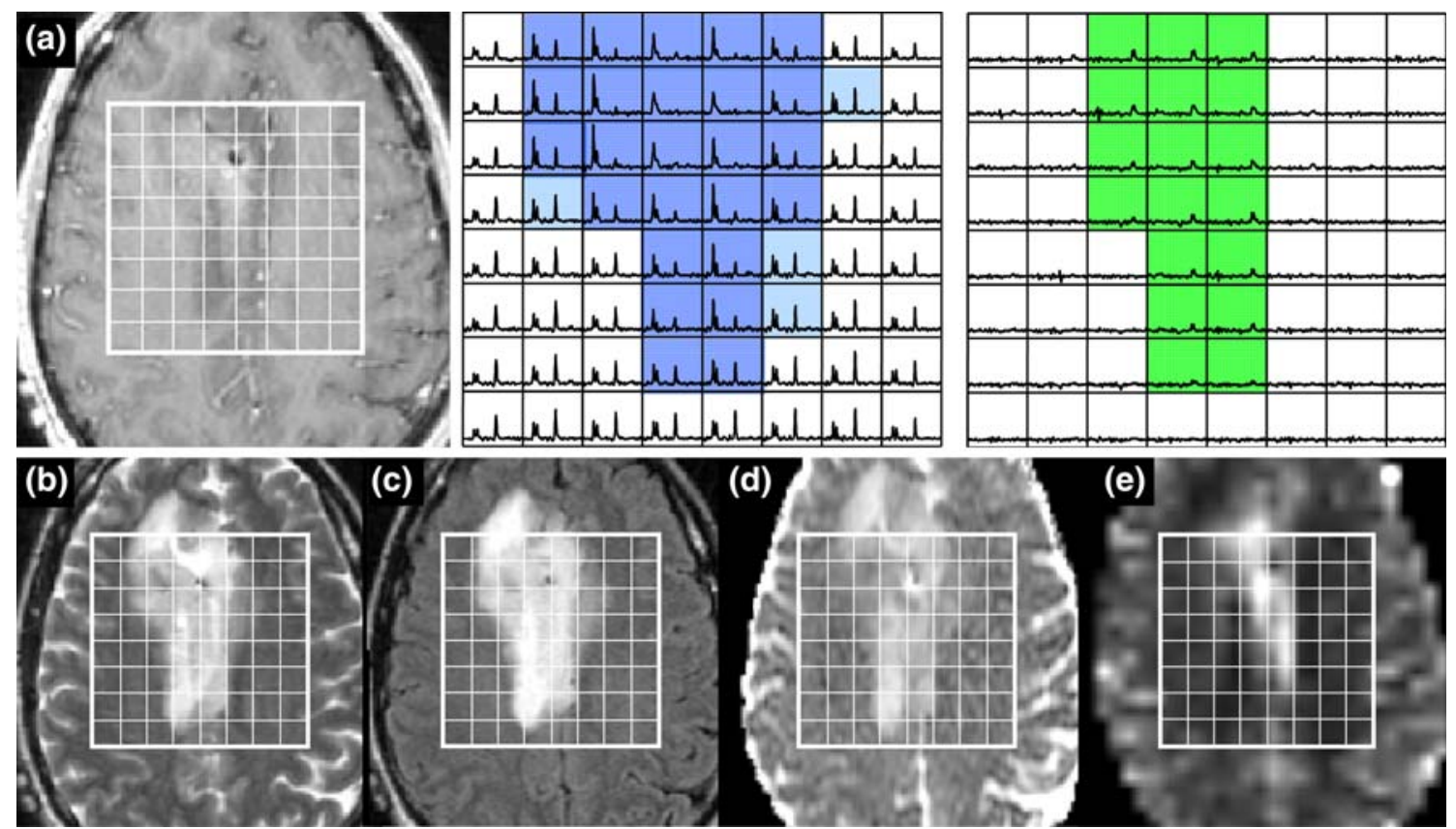

Fig. 6 Patient with an ODII: a is a post-Gadolinium T1-weighted image, $\mathbf{b}$ is a FSE image, $\mathbf{c}$ is a FLAIR image, $\mathbf{d}$ is an ADC map, and $\mathbf{e}$ is a map of $\mathrm{nPH}$. The lactate edited spectra correspond to the sum (choline, creatine, NAA, and lipid if it is present) and the difference

ADC was relative high (medians 1.99 and 2.49) and the nPH (medians 0.49 and 0.73) was lower than in NAWM.

The patient in Fig. 6 had an ODII with quite different characteristics. The additional green voxels in the lactate- (which would show lactate if present). Light blue voxels show $2<\mathrm{CNI}<3$ and dark blue voxels show $\mathrm{CNI}>3$. Note the elevated $\mathrm{nPH}$, lower $\mathrm{nADC}$ values and the large number of voxels with visible but low lactate (green)

edited spectra highlighted areas which had elevated lactate peaks. The median $\mathrm{nADC}$ in the region with $\mathrm{CNI}>2$ was 1.54 and the median perfusion was 1.86 . There were 72 voxels with $\mathrm{CNI}>2$ and 54 with $\mathrm{CNI}>3$. The median CNI 

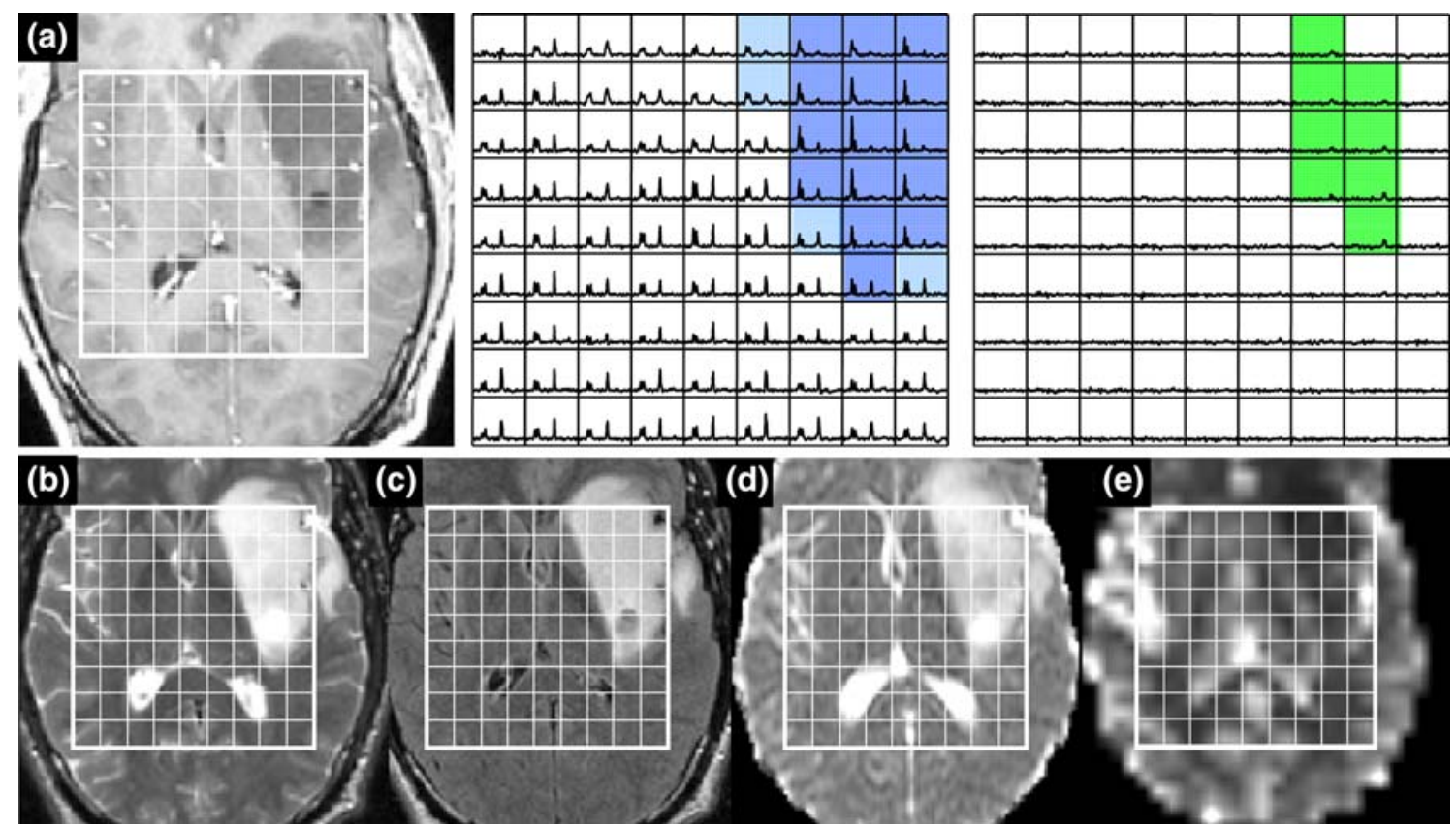

Fig. 7 Patient with an OAIII: a is a post-Gadolinium T1-weighted image, $\mathbf{b}$ is a FSE image, $\mathbf{c}$ is a FLAIR image, $\mathbf{d}$ is an ADC map, and $\mathbf{e}$ is a map of $\mathrm{nPH}$. The lactate edited spectra correspond to the sum (choline, creatine, NAA, and lipid if it is present) and the difference (which would show lactate if present). Light blue voxels show $2<\mathrm{CNI}<3$ and dark blue voxels show $\mathrm{CNI}>3$. Note the low $\mathrm{nPH}$, lower $\mathrm{nADC}$ values and the voxels with visible but low lactate (green)
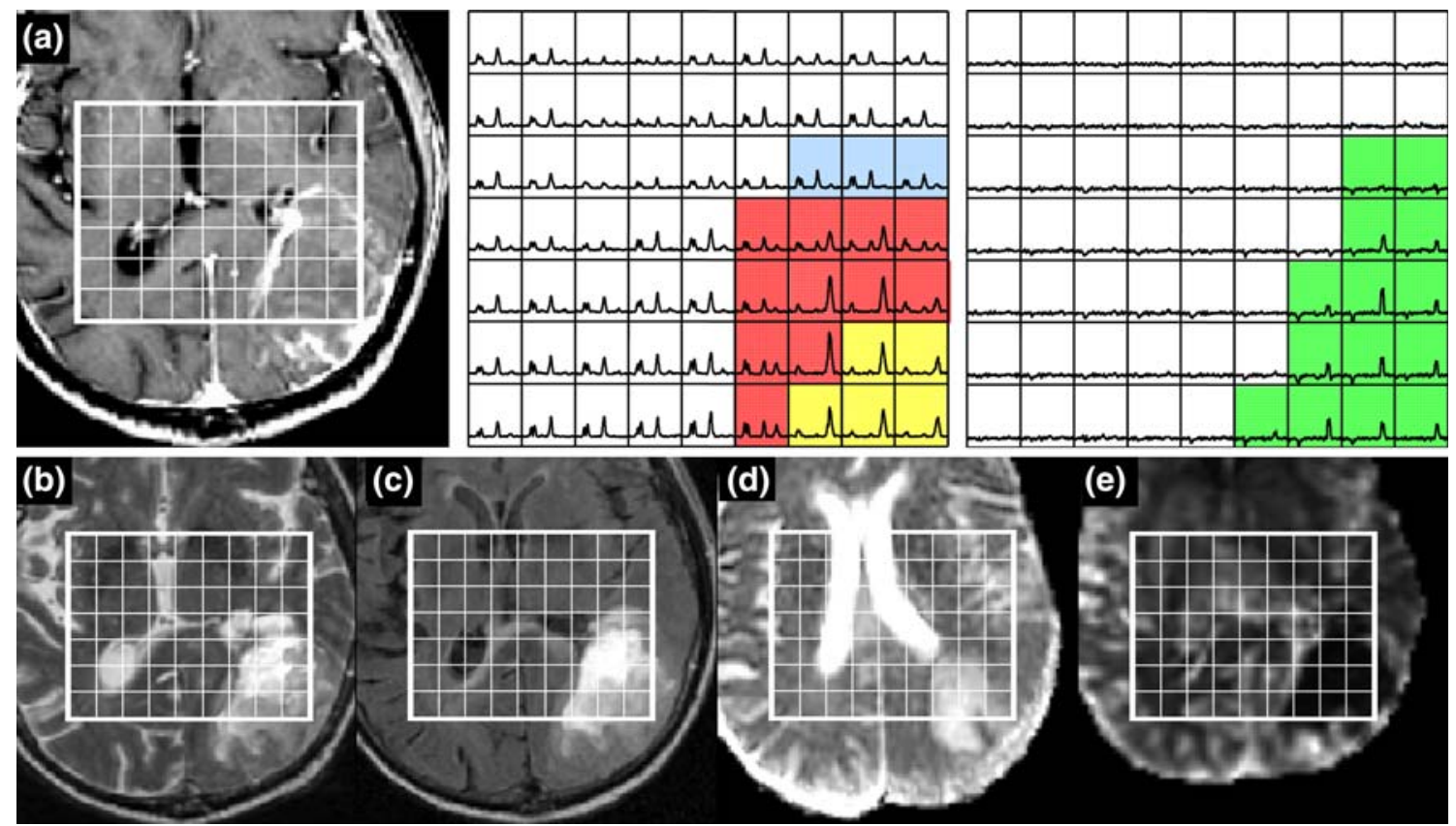

Fig. 8 Patient with a grade IV glioma: a is a post-Gadolinium T1-weighted image, $\mathbf{b}$ is a FSE image, $\mathbf{c}$ is a FLAIR image, $\mathbf{d}$ is an $\mathrm{ADC}$ map, and $\mathbf{e}$ is a map of $\mathrm{nPH}$. The lactate edited spectra correspond to the sum (choline, creatine, NAA, and lipid if it is present) and the difference (which would show lactate if present).
Light blue voxels show $\mathrm{CNI}>2$ and red voxels show $\mathrm{CNI}>2$ and elevated lipid, yellow voxels show low CNI with elevated lipid and green voxels show elevated latcate. Note the low $\mathrm{nPH}$ in the necrosis and the variable $\mathrm{nADC}$ values. Survival $=139$ days 

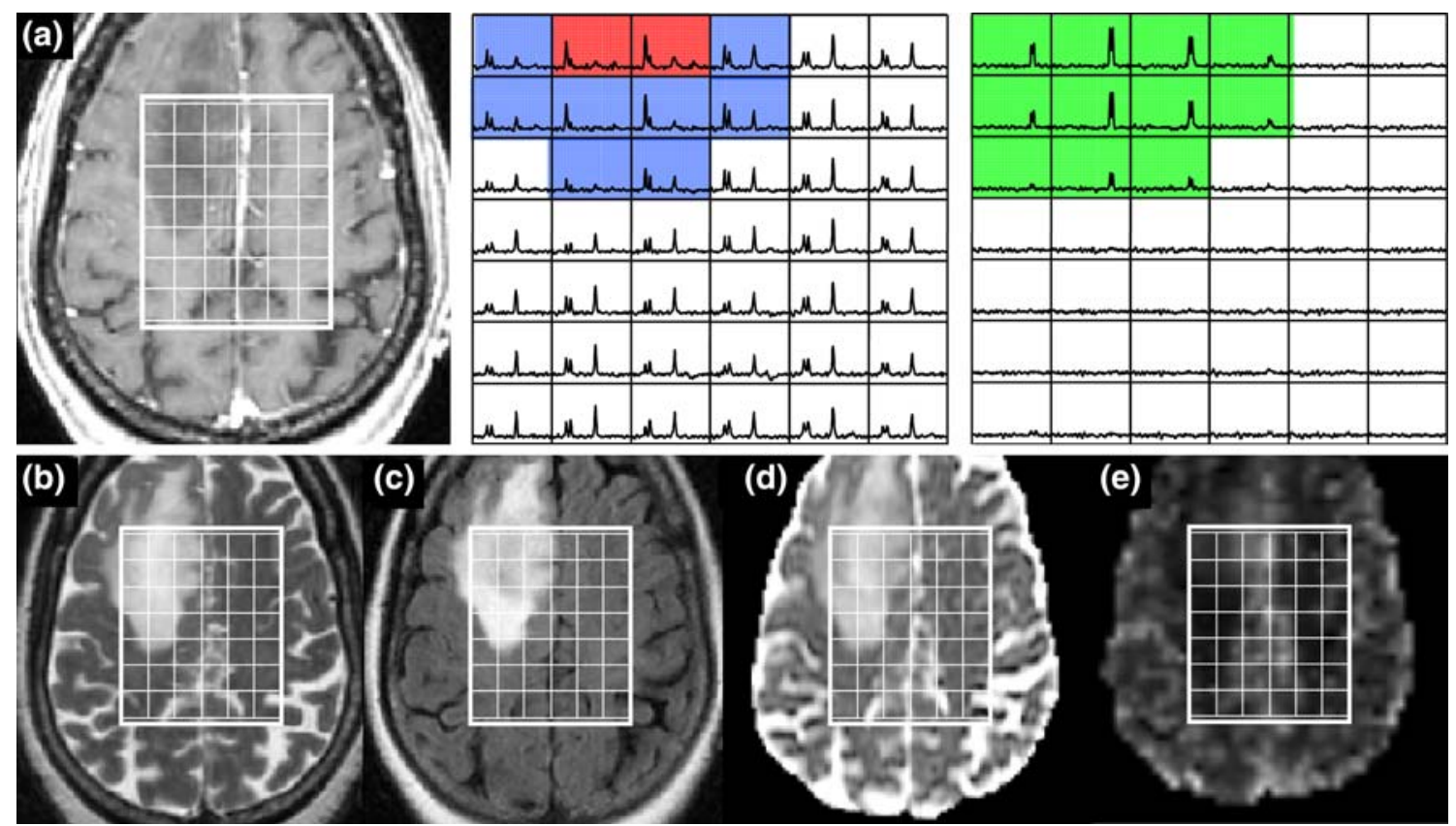

Fig. 9 Patient with a grade III glioma: a is a post-Gadolinium T1-weighted image, $\mathbf{b}$ is a FSE image, $\mathbf{c}$ is a FLAIR image, $\mathbf{d}$ is an $\mathrm{ADC}$ map, and $\mathbf{e}$ is a map of $\mathrm{nPH}$. The lactate edited spectra correspond to the sum (choline, creatine, NAA, and lipid if it is present) and the difference (which would show lactate if present). Light blue voxels show $\mathrm{CNI}>2$ and red voxels show $\mathrm{CNI}>2$ and elevated lipid and the green voxels show elevated latcate. Note the low $\mathrm{nPH}$ in the lesion and the variable $\mathrm{nADC}$ values. Survival $=610$ days
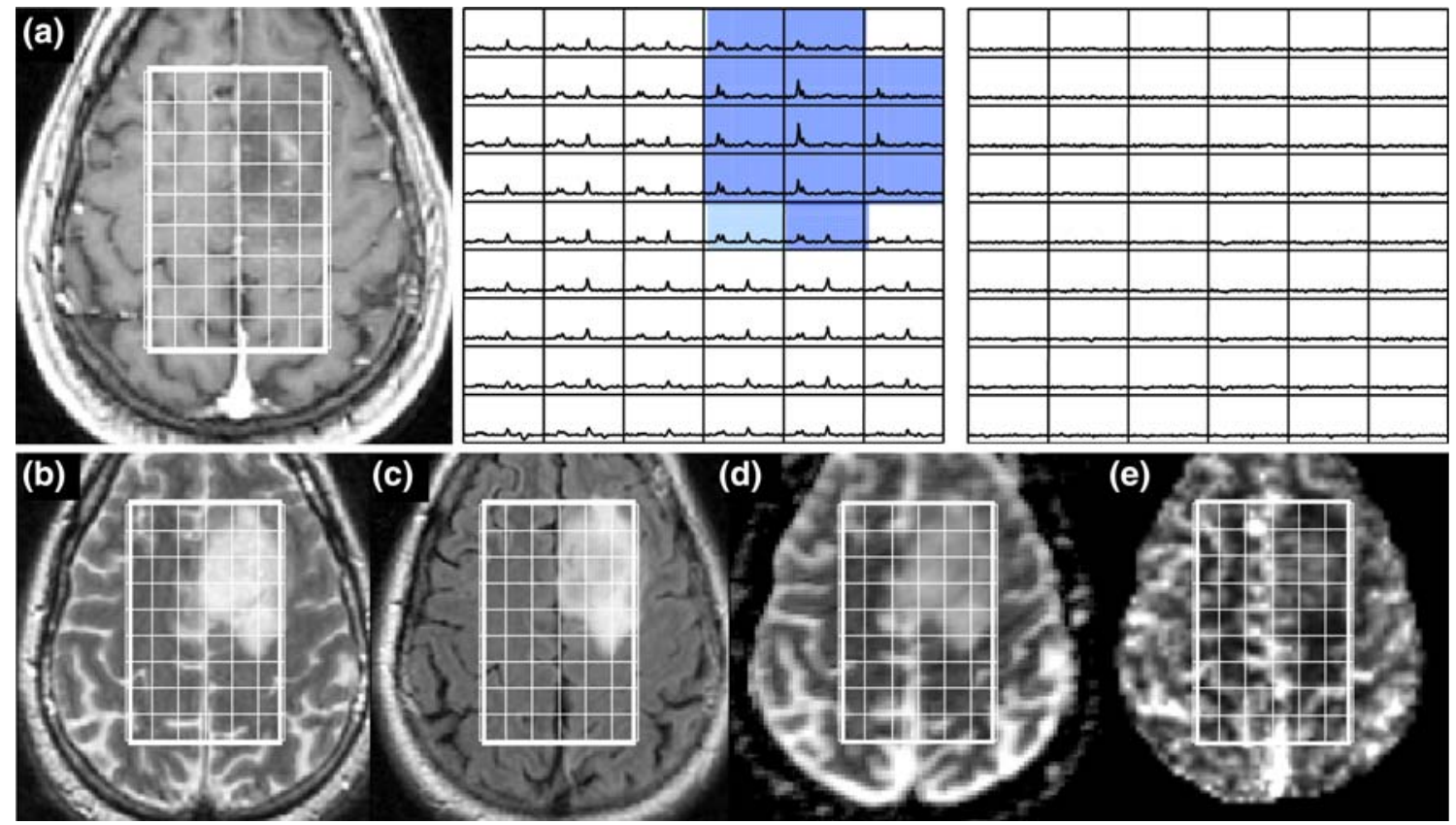

(d)

Fig. 10 Patient with an atypical grade IV glioma: a is a postGadolinium T1-weighted image, $\mathbf{b}$ is a FSE image, $\mathbf{c}$ is a FLAIR image, $\mathbf{d}$ is an ADC map, and $\mathbf{e}$ is a map of $\mathrm{nPH}$. The lactate edited spectra correspond to the sum (choline, creatine, NAA, and lipid if it is present) and the difference (which would show lactate if present). Light blue voxels show $3>\mathrm{CNI}>2$ and the dark blue show $\mathrm{CNI}>3$. Note the intermediate levels of $\mathrm{nPH}$ in the lesion and low nADC values. Survival $=985$ days 
Table 5 The median number of voxels that have elevated CNI, the median CNI value and the maximum CNI value within the region having $\mathrm{CNI}>2$

\begin{tabular}{lllll}
\hline Grade & Voxels CNI $>2$ & Voxels CNI $>3$ & Median CNI for CNI $>2$ voxels & Max CNI value \\
\hline ACII & 20 & 7 & 2.9 & 5.7 \\
$N=14$ & $4-55$ & $0-37$ & $2.3-3.7$ & $3.5-9.5$ \\
OAII & 15 & 7 & 2.9 & 6.1 \\
$N=13$ & $5-47$ & $0-32$ & $2.4-4.2$ & $3.5-9.2$ \\
ODII & 22 & 10 & 2.7 & 6.4 \\
$N=20$ & $1-72$ & $0-54$ & $2.3-6.3$ & $2.8-16.6$ \\
III & 27 & 15 & 3.1 & 7.1 \\
$N=25$ & $2-69$ & $0-58$ & $2.2-5.6$ & $3.5-18.7$ \\
IV & 33 & 20 & 3.3 & 7.4 \\
$N=40$ & $5-84$ & $0-79$ & $2.3-9.4$ & $3.0-27.3$ \\
\hline
\end{tabular}

Values are given as median and range to show their large variability. The median ratio of the number of voxels with CNI $>2$ to the number of voxels within the T2 lesion that were included in the PRESS volume were $0.55,0.47$, and 0.97 for the ACII, OAII, and ODII subtypes and were 0.75 and 0.62 for the grade III and grade IV lesions

was 3.13 and the maximum CNI was 16.3. Although the lactate covered a large number of voxels, the intensity in each was moderate, with the maximum Lac/nNAA being 0.45 and the sum (Lac/nNAA) being 11.7 .

Variations in the amount of lactate and lipid within the metabolic lesion

Table 6 gives the variations in lactate and lipid parameters. While there was a small number of patients with grade II glioma who had moderate lactate peaks, the overall median, maximum and sum of values were relatively low. A larger number of the patients with grade III glioma had elevated lactate. Figure 7 gives an example of a patient with a non-enhancing OAIII. The number of voxels with CNI $>2$ was 68 and the number with CNI $>3$ was 49 , with the median CNI being 5.6 and the maximum being 15.0. Moderate lactate peaks were present with a maximum Lac/ nNAA of 0.36 and sum (Lac/nNAA) of 8.2. There were no significant lipid peaks, the nADC was 1.79 and the median perfusion was lower than in NAWM.
Patients with grade IV glioma frequently had spectra with both elevated lactate and lipid peaks. Figure 8 gives an example of such a lesion, where the red voxels have both CNI $>2$ and significant lipid, while the yellow voxels have lipid but with much lower CNI values. In this case the total number of voxels with CNI $>2$ was only 19 and those with $\mathrm{CNI}>3$ was one. The maximum $\mathrm{CNI}$ was 3.5 , the maximum Lip/nNAA was 2.2 and the maximum Lac/ nNAA was 1.11. Perfusion was low in the majority of the lesion due to the high degree of necrosis, but in the border of the CE lesion the 75th percentile of $\mathrm{nPH}$ was 2.7 times the value in NAWM. The nADC was variable but was relatively low, with the median value being 1.3 and the vol (nADC $<1.5$ ) being $58 \mathrm{cc}$. The overall survival for this patient was 139 days (4.5 months) after diagnosis.

\section{Patients with atypical findings}

While the results that have been reported held for the majority of patients, there were a small number of outliers in each subpopulation, who had MR parameters that were consistent

Table 6 Levelsi of lipid and lactate normalized to the level of NAA in normal appearing white matter

\begin{tabular}{|c|c|c|c|c|c|c|}
\hline Grade & Lip median in $\mathrm{CNI}>2$ & Lip max in $\mathrm{CNI}>2$ & Sum (Lip) In CNI >2 & Lac median In CNI >2 & Lac max in $\mathrm{CNI}>2$ & Sum $(\mathrm{Lac})$ in $\mathrm{CNI}>2$ \\
\hline II & -0.03 & 0.21 & 0.40 & 0.03 & 0.14 & 1.84 \\
\hline$N=40$ & $\mathrm{sd}=0.06$ & $\mathrm{sd}=0.13$ & $\mathrm{sd}=0.98$ & $\mathrm{sd}=0.08$ & $\mathrm{sd}=0.15$ & $\mathrm{sd}=2.93$ \\
\hline III & 0.04 & 0.19 & 0.66 & $0.12 *$ & $0.21 *$ & $2.88^{*}$ \\
\hline$N=25$ & $\mathrm{sd}=0.03$ & $\mathrm{sd}=0.16$ & $\mathrm{sd}=1.40$ & $\mathrm{sd}=0.12$ & $\mathrm{sd}=0.42$ & $\mathrm{sd}=4.48$ \\
\hline IV & $0.14 *$ & $0.55^{*}$ & $3.94 *$ & $0.17 *$ & $0.45^{*}$ & $5.29 *$ \\
\hline$N=35$ & $\mathrm{sd}=0.17$ & $\mathrm{sd}=0.83$ & $\mathrm{sd}=7.55$ & $\mathrm{sd}=0.08$ & $\mathrm{sd}=0.29$ & $\mathrm{sd}=5.32$ \\
\hline
\end{tabular}

Values are evaluated within voxels that have $\mathrm{CNI}>2$ to avoid cysts or necrosis. Four of the patients from the grade II population were eliminated from the analysis of lipid after visual examination of the spectral data due to concern about the possibility of contamination from signals arising from subcutaneous lipids. The values estimated from analysis for the grade II subtypes gave similar results and so only the overall results are given 
with different biological characteristics. An example of one such patient with a grade III lesion that has extremely high lactate and voxels with low but significant lipid is seen in Fig. 9. The number of voxels with $\mathrm{CNI}>2$ was 31 , the number with $\mathrm{CNI}>3$ was 27 , the median $\mathrm{CNI}$ was 5.2 and the maximum was relatively high at 12.7 . The median $\mathrm{nPH}$ was 1.4, which given the location, does not appear to be elevated above comparable tissue on the contralateral hemisphere. The median nADC was 1.74 and the vol (nADC < 1.5) was $13.0 \mathrm{cc}$. Of particular note is that this patient had a relatively short overall survival for the given diagnosis of grade III glioma, which was 610 days (20 months).

In contrast, the patient in Fig. 10 had a grade IV glioma in a similar location but with MR parameters that would have been more consistent with an ODII or grade III glioma. The maximum Lac/nNAA was 0.19 and the maximum Lip/ nNAA was 0.28 . The choline levels were relatively high with the number of voxels with $\mathrm{CNI}>2$ being 50 , the number with CNI $>3$ being 38 , the median CNI being 4.8 and the maximum CNI being 27.1. The nADC values were relatively high with median 1.84 and the perfusion was moderate with median nPH of 1.35. Interestingly the overall survival for this patient was relatively long for a grade IV glioma at 985 days or 33 months after diagnosis.

\section{Discussion}

Previous studies have demonstrated the value of individual physiologic parameters in the assessment of glioma versus other etiologies of an intracranial mass. In this study we were able to show that the integration of MR parameters obtained from both anatomic and metabolic/physiologic imaging techniques prior to surgical resection can be relevant in characterizing untreated gliomas of various grades and histology. These methodologies were uniformly acquired in a clinical setting as an extension of the examination that is performed for the purposes of image guided surgery. Quantitative parameters were defined, which use values in normal appearing white matter as an internal reference and are relatively robust to variations in data acquisition parameters. While the analysis was performed offline and compared retrospectively with clinical data, the majority of the software that was used had a modest computational burden and could have been integrated into the radiological evaluation of the patient without causing an unwanted delay. There are two major applications arising from the results presented in this study. The first is in directing surgical resection and tissue sampling to the most appropriate locations of the tumor in order to make a histological diagnosis. The second is in potentially providing information to the oncologist that can be considered in stratifying patients for clinical trials in order to select the treatment that best matches the profile of each specific tumor.

Integration of anatomic and physiologic imaging parameters and proposal of a management algorithm for tissue sampling of newly diagnosed presumed glioma

For a patient who has had the specified MR protocol performed prior to resection, the first stage of analysis is to examine the anatomic images to see whether the lesion can be classified as (1) non-enhancing, (2) enhancing with no necrosis or (3) enhancing with necrosis. If the tumor is in category one, the lesion is more likely to be a grade II or grade III glioma. The next stage of the analysis is to look at the nADC values using the color maps that are illustrated in Fig. 3. If the $\mathrm{nADC}$ values are in the range that makes the resulting map entirely blue (see Fig. 3a), then it most likely to be a grade II astrocytoma. Absence of lipid, low lactate and $\mathrm{nPH}$ provide further evidence that is suggestive of this histology. To obtain a representative tissue sample from the T2 lesion, it would be important to target the voxel with the highest CNI, which is most likely to correspond to a region of proliferation or high cell density.

If the nADC color map shows a heterogenous mixture of blue and pink regions within the lesion (as is seen in Fig. 3c), as well as low nPH, lactate and lipid then it is most likely to be a grade II oligoastrocytoma. Tissue sampling should be directed at both astro-(blue) and oligolike (pink) components, with at least one of these being selected to have high CNI. This would provide the best chance of distinguishing oligoastrocytomas that have grade II versus grade III histology. If, on the other hand, the nADC color map is uniformly pink then the lesion is most likely to be a non-enhancing grade II oligodendroglioma. Lactate may be present but, as is seen in Fig. 6, is usually low for such lesions. There may also be moderate nPH and weak enhancement. Tissue sampling should be directed to the voxel with the highest CNI in order to most effectively distinguish between tumors of grade II and grade III.

If the lesion is in category two (enhancement but no visible necrosis) there are a number of the parameters that can be used to assist in inferring tumor grade. These include the volume of the enhancing volume relative to the overall $\mathrm{T} 2$ lesion, the volume of the $\mathrm{T} 2$ lesion that has nADC less than 1.5, the presence of elevated blood volume $(\mathrm{nPH}>3.0)$ and elevated lipid (Lac/nNAA > 0.25). These are all indicative of grade IV as opposed to grade III glioma. While, as is seen for the patient in Fig. 10, the absence of these characteristics may not always preclude a diagnosis of grade IV glioma, they are predictive of more favorable survival. Areas within the CE lesion that should be targeted for tissue sampling in order to distinguish 
between grade III and grade IV glioma are those with the highest $\mathrm{nPH}$ and the maximum CNI.

Our analysis indicates that all of the lesions in category three (enhancing with areas of visible necrosis) have grade IV histology. Those for which a large percentage of the T2 lesion is enhancing and necrotic are also predicted to have poor survival [34]. While the existence of low nADC in sub-regions of the $\mathrm{CE}$ lesion are associated with poor outcome for grade IV glioma, it may be difficult to separate these values from the high nADC in areas of necrosis. Another complication for the evaluation of large enhancing and necrotic grade IV gliomas is the relatively large mass effect and the existence of edema, which confuse the assessment of the spatial extent of the T2 lesion. The CNI is valuable here because it has been shown to distinguish between tumor and edema [30].

Potential confounding results with respect to histology and grade

Previous studies have reported that $\mathrm{nADC}$ is inversely correlated with tumor cellularity [46]. Our results have shown that while this may be the case for area of macroscopic tumor within the enhancing volume of grade IV glioma, it is not consistent with the values in grade II and grade III glioma. These remain high in regions with elevated choline and decreased NAA that are expected to correspond to areas of increased cellularity [41, 47]. One possible interpretation of such findings is that $\mathrm{nADC}$ values are influenced by a combination of difference in tissue architecture and tumor cell density. In low grade astrocytoma (ACII), where the emphasis is on the breakdown of the normal structure of white matter, the dominant process gives a high nADC, but with a reduction in NAA and moderate increase in choline that is caused by infiltrative tumor. In high grade glioma the majority of the CE lesion has been completely replaced by tumor cells and so low nADC reflects high tumor cell density, as well as elevated choline and low NAA (high CNI). From our analysis it is clear that while the CNI indicates the presence of tumor and is valuable for defining the extent of the metabolic lesion, it can be very high in all tumor grades and its presence does not necessarily mean that the tumor is going to progress rapidly.

Elevated lipid [43] and high blood volume [48] have also been presented as characteristics of high grade glioma. The presence of lipid in grade IV glioma is thought to be due to cellular breakdown due to necrosis and apoptosis. While care must be taken to ensure that the lipid peaks are truly from the tumor and are not caused by aliasing of regions from subcutaneous fat, there is no doubt that it is an important diagnostic indicator [34]. The elevated blood volume is due to increased and abnormal angiogenesis, which is a hallmark of grade IV glioma. The exception is the finding of elevated blood volume seen in grade II oligodendroglioma [14, 15]. As presented in the management algorithm, evaluation of anatomic imaging (e.g., degree of contrast enhancement) and ADC color maps in addition to perfusion parameters should be integrated in the assessment rather than using an individual characteristic alone.

\section{Future studies}

Validation of these findings of integrating standard anatomic imaging and uniformly acquired physiologic imaging will be performed in a separate prospective study of patients with newly diagnosed presumed glioma. We also plan to correlate these findings with clinical characteristics and patient outcome to assess their prognostic significance. The next step is to integrate this technology with the acquisition of image guided tissue samples in order to further elucidate their biological significance and make direct correlations with molecular markers of hypoxia, cell density, proliferation, and angiogenesis.

\section{Conclusions}

Our study has identified non-invasive MR biomarkers that are derived from integrating anatomic, metabolic, and physiological imaging data that are valuable in characterizing newly diagnosed glioma. The long-term goal is to examine the prognostic significance of these parameters, validate the biological correlates, evaluate how these endpoints change in response to specific therapies and to perform a similar study of the characteristics in recurrent glioma.

Acknowledgments The authors would like to thank Inas Khayal, Esin Ozturk-Isik, Wei Bian, and Janine Lupo for useful discussions and assistance with the interpretation of the data. Financial support: This work was supported by NIH grants R01 CA059880; R01 CA116041; PO1 CA 118816; SPORE P50 CA97257.

Open Access This article is distributed under the terms of the Creative Commons Attribution Noncommercial License which permits any noncommercial use, distribution, and reproduction in any medium, provided the original author(s) and source are credited.

\section{References}

1. Kleihues P, Cavence WK (2000) Pathology and genetics of tumors of the nervous system. IARC Press, Lyon

2. Mason WP, Krol GS, DeAngelis LM (1996) Low-grade oligodendroglioma responds to chemotherapy. Neurology 46(1): 203-207

3. Leighton C, Fisher B, Bauman G, Depiero S, Stitt L, MacDonald D, Cairncross G (1997) Supratentorial low-grade glioma in adults: an analysis of prognostic factors and timing of radiation. J Clin Oncol 15(4):1289-1290 
4. Perry JR, Louis DN, Cairncross JG (1999) Current treatment of oligodendrogliomas. Arch Neurol 56:434-436. doi:10.1001/ archneur.56.4.434

5. Sasaki H, Zlatescu MC, Betensky RA, Johnk LB, Cutone AN, Cairncross JG, Louis DN (2002) Histopathological-molecular genetic correlations in referral pathologist-diagnosed low-grade "oligodendroglioma". J Neuropathol Exp Neurol 61(1):58-63

6. Dean BL, Drayer BP, Bird CR et al (1990) Gliomas: classification with MR imaging. Radiology 174:411-415

7. Cha S (2006) Update on brain tumor imaging: from anatomy to physiology AJNR. AJNR Am J Neuroradiol 27(3):475-487

8. Lee PL, Gonzalez RG (2000) Magnetic resonance spectroscopy of brain tumors. Curr Opin Oncol 12:199-204. doi:10.1097/ 00001622-200005000-00003

9. Vigneron D, Bollen A, McDermott M et al (2001) Three-dimensional magnetic resonance spectroscopic imaging of histologically confirmed brain tumors. Magn Reson Imaging 19:89-101. doi: $10.1016 / \mathrm{S} 0730-725 \mathrm{X}(01) 00225-9$

10. Nelson SJ (2001) Analysis of volume MRI and MR spectroscopic imaging data for the evaluation of patients with brain tumors. Magn Reson Med 46:228-239. doi:10.1002/mrm.1183

11. Sugahara T, Korogi Y, Kochi M, Ikushima I, Hirai T, Okuda T, Shigematsu Y, Liang L, Ge Y, Ushio Y, Takahashi M (1998) Correlation of MR imaging-determined cerebral blood volume maps with histologic and angiographic determination of vascularity of gliomas. AJR Am J Roentgenol 171(6):1479-1486

12. Petrella JR, Provenzale JM (2000) MR perfusion imaging of the brain: techniques and applications. AJR Am J Roentgenol 175(1): 207-219

13. Cha S, Knopp EA, Johnson G, Wetzel SG, Litt AW, Zagzag D (2002) Intracranial mass lesions: dynamic contrast-enhanced susceptibility-weighted echo-planar perfusion MR imaging. Radiology 223(1):11-29. doi:10.1148/radiol.2231010594

14. Cha S, Tihan T, Crawford F, Fischbein NJ, Chang S, Bollen A, Nelson SJ, Prados M, Berger MS, Dillon WP (2005) Differentiation of low-grade oligodendrogliomas from low-grade astrocytomas by using quantitative blood-volume measurements derived from dynamic susceptibility contrast-enhanced MR imaging. AJNR Am J Neuroradiol 26(2):266-273

15. Lev MH, Ozsunar Y, Henson JW, Rasheed AA, Barest GD, Harsh GR, Fitzek MM, Chiocca EA, Rabinov JD, Csavoy AN, Rosen BR, Hochberg FH, Schaefer PW, Gonzalez RG (2004) Glial tumor grading and outcome prediction using dynamic spinecho MR susceptibility mapping compared with conventional contrast-enhanced MR: confounding effect of elevated rCBV of oligodendrogliomas. AJNR Am J Neuroradiol 25:214-221

16. Whitmore RG, Krejza J, Kapoor GS, Huse J, Woo JH, Bloom S, Lopinto J, Wolf RL, Judy K, Rosenfeld MR, Biegel JA, Melhem ER, O'Rourke DM (2007) Prediction of oligodendroglial tumor subtype and grade using perfusion weighted magnetic resonance imaging. J Neurosurg 107(3):600-609. doi:10.3171/JNS-07/09/0600

17. Basser PJ, Pierpaoli C (1996) Microstructural and physiological features of tissues elucidated by quantitative-diffusion-tensor MRI. J Magn Reson B 111(3):209-219. doi:10.1006/jmrb.1996. 0086

18. Brunberg JA, Chenevert TL, McKeever PE, Ross DA, Junck LR, Muraszko KM, Dauser R, Pipe JG, Betley AG (1995) In vivo MR determination of water diffusion coefficients and diffusion anisotropy: correlation with structural alteration in gliomas of the cerebral hemispheres. AJNR Am J Neuroradiol 16:361-371

19. Sugahara T, Korogi Y, Kochi M, Ikushima I, Shigematu Y, Hirai T, Okuda T, Liang L, Ge Y, Komohara Y, Ushio Y, Takahashi M (1999) Usefulness of diffusion-weighted MRI with echo-planar technique in the evaluation of cellularity in gliomas. J Magn Reson Imaging 9(1):53-60. doi:10.1002/(SICI)1522-2586(199901)9:1< 53::AID-JMRI7>3.0.CO;2-2
20. Tozer DJ, Jäger HR, Danchaivijitr N, Benton CE, Tofts PS, Rees JH, Waldman AD (2007) Apparent diffusion coefficient histograms may predict low-grade glioma subtype. NMR Biomed 20(1):49-57. doi:10.1002/nbm.1091

21. Jenkinson MD, Smith TS, Brodbelt AR, Joyce KA, Warnke PC, Walker C (2007) Apparent diffusion coefficients in oligodendroglial tumors characterized by genotype. J Magn Reson Imaging 26(6):1405-1412. doi:10.1002/jmri.21062

22. Chen J, Xia J, Zhou YC, Xia LM, Zhu WZ, Zou ML et al (2005) Correlation between magnetic resonance diffusion weighted imaging and cell density in astrocytoma. Zhonghua Zhong Liu Za Zhi 27:309-311

23. Chenevert TL, Stegman LD, Taylor JM, Robertson PL, Greenberg HS, Rehemtulla A et al (2000) Diffusion magnetic resonance imaging: an early surrogate marker of therapeutic efficacy in brain tumors. J Natl Cancer Inst 92:2029-2036. doi:10.1093/jnci/92. 24.2029

24. Croteau D, Scarpace L, Hearshen D, Gutierrez J, Fisher JL, Rock JP, Mikkelsen T (2001) Correlation between magnetic resonance spectroscopy imaging and image-guided biopsies: semiquantitative and qualitative histopathological analyses of patients with untreated glioma. Neurosurgery 49(4):823-829. doi:10.1097/ 00006123-200110000-00008

25. Rijpkema M, Schuuring J, van der Meulen $Y$, van der Graaf M, Bernsen H, Boerman R, van der Kogel A, Heerschap A (2003) Characterization of oligodendrogliomas using short echo time $1 \mathrm{H}$ MR spectroscopic imaging. NMR Biomed 16(1):12-18. doi: $10.1002 / \mathrm{nbm} .807$

26. Jenkinson MD, Smith TS, Joyce K, Fildes D, du Plessis DG, Warnke PC, Walker C (2005) MRS of oligodendroglial tumors: correlation with histopathology and genetic subtypes. Neurology 64(12):2085-2089. doi:10.1212/01.WNL.0000165998.73779.D9

27. Oh J, Henry RG, Pirzkall A, Lu Y, Li X, Catalaa I et al (2004) Survival analysis in patients with glioblastoma multiforme: predictive value of choline-to- $N$-acetylaspartate index, apparent diffusion coefficient, and relative cerebral blood volume. J Magn Reson Imaging 19:546-554. doi:10.1002/jmri.20039

28. Pirzkall A, McKnight TR, Graves EE, Carol MP, Sneed PK, Wara WW et al (2001) MR-spectroscopy guided target delineation for high-grade gliomas. Int J Radiat Oncol Biol Phys 50:915-928. doi: 10.1016/S0360-3016(01)01548-6

29. Giese A, Westphal M (2001) Treatment of malignant glioma: a problem beyond the margins of resection. J Cancer Res Clin Oncol 127:217-225. doi:10.1007/s004320000188

30. McKnight TR, von dem Bussche MH, Vigneron DB, Lu Y, Berger MS, McDermott MW et al (2002) Histopathological validation of a three-dimensional magnetic resonance spectroscopy index as a predictor of tumor presence. J Neurosurg 97:794-802

31. Kuznetsov YE, Caramanos Z, Antel SB, Preul MC, Leblanc R, Villemure JG et al (2003) Proton magnetic resonance spectroscopic imaging can predict length of survival in patients with supratentorial gliomas. Neurosurgery 53:565-574. doi:10.1227/01.NEU. 0000079331.21178.8E discussion 574-576

32. Li X, Jin H, Lu Y, Oh J, Chang S, Nelson SJ (2004) Identification of MRI and $1 \mathrm{H}$ MRSI parameters that may predict survival for patients with malignant gliomas. NMR Biomed 17:10-20. doi: 10.1002/nbm.858

33. Saraswathy S, Crawford FW, Lamborn KR, Pirzkall A, Chang S, Cha S, Nelson SJ (2009) Evaluation of MR markers that predict survival in patients with newly diagnosed GBM prior to adjuvant therapy. J Neurooncol 91(1):69-81. doi:10.1007/s11060-008-9685-3

34. Crawford FW, Khayal IS, McGue C, Saraswathy S, Pirzkall A, Cha S, Lamborn KR, Chang SM, Berger MS, Nelson SJ (2009) Relationship of pre-surgery metabolic and physiological MR imaging parameters to survival for patients with untreated GBM. J Neurooncol 91:337-351. doi:10.1007/s11060-008-9719-x 
35. Nelson SJ (2001) Analysis of volume MRI and MR spectroscopic imaging data for the evaluation of patients with brain tumors. Magn Reson Med 46(2):228-239. doi:10.1002/mrm.1183

36. Nelson SJ, Nalbandian AB, Proctor E, Vigneron DB (1994) Registration of images from sequential MR studies of the brain. J Magn Reson Imaging 4:877-883. doi:10.1002/jmri.1880040621

37. Zhang Y, Brady M, Smith S (2001) Segmentation of brain MR images through a hidden Markov random field model and the expectation-maximization algorithm. IEEE Trans Med Imaging 20:45-57. doi:10.1109/42.906424

38. Lupo JM, Cha S, Chang SM, Nelson SJ (2005) Dynamic susceptibility-weighted perfusion imaging of high-grade gliomas: characterization of spatial heterogeneity. AJNR Am J Neuroradiol 26:1446-1454

39. Cha S, Lupo JM, Chen MH, Lamborn KR, McDermott MW, Berger MS, Nelson SJ, Dillon WP (2007) Differentiation of glioblastoma multiforme and single brain metastasis by peak height and percentage of signal intensity recovery derived from dynamic susceptibility-weighted contrast-enhanced perfusion MR imaging. AJNR Am J Neuroradiol 28:1078-1084. doi:10.3174/ajnr.A0484

40. Hartkens T, Rueckert D, Schnabel JA, Hawkes DJ, Hill DLG (2002) VTK CISG Registration Toolkit: an open source software package for affine and non-rigid registration of single- and multimodal 3D images. [abstract] BVM 2002. Springer-Verlag, Leipzig

41. Khayal IS, Crawford FW, Saraswathy S, Lamborn KR, Chang SM, Cha S, McKnight TR, Nelson SJ (2008) Relationship between choline and apparent diffusion coefficient in patients with gliomas. J Magn Reson Imaging 27(4):718-725. doi:10.1002/jmri.21288

42. Tran TK, Vigneron DB, Sailasuta N, Tropp J, Le Roux P, Kurhanewicz J et al (2000) Very selective suppression pulses for clinical MRSI studies of brain and prostate cancer. Magn Reson Med 43:23-33. doi:10.1002/(SICI)1522-2594(200001)43:1<23:: AID-MRM4 $>3$.0.CO;2-E

43. Li X, Vigneron DB, Cha S, Graves EE, Crawford F, Chang SM, Nelson SJ (2005) Relationship of MR-derived lactate, mobile lipids, and relative blood volume for gliomas in vivo. AJNR Am J Neuroradiol 26(4):760-769

44. McKnight TR, Noworolski SM, Vigneron DB, Nelson SJ (2001) An automated technique for the quantitative assessment of 3D-MRSI data from patients with glioma. J Magn Reson Imaging 13:167-177. doi:10.1002/1522-2586(200102)13:2<167::AIDJMRI1026 $>3.0 . \mathrm{CO} ; 2-\mathrm{K}$

45. Nelson SJ, Cha S (2003) Imaging glioblastoma multiforme. Cancer J 9:134-145. doi:10.1097/00130404-200303000-00009

46. Gupta RK, Cloughesy TF, Sinha U, Garakian J, Lazareff J, Rubino G, Rubino L, Becker DP, Vinters HV, Alger JR (2000) Relationships between choline magnetic resonance spectroscopy, apparent diffusion coefficient and quantitative histopathology in human glioma. J Neurooncol 50(3):215-226. doi:10.1023/A:1006 431120031

47. Catalaa I, Henry R, Dillon WP, Graves EE, McKnight TR, Lu Y et al (2006) Perfusion, diffusion and spectroscopy values in newly diagnosed cerebral gliomas. NMR Biomed 19:463-475. doi: 10.1002/nbm. 1059

48. Law M, Yang S, Wang H, Babb JS, Johnson G, Cha S et al (2003) Glioma grading: sensitivity, specificity, and predictive values of perfusion MR imaging and proton MR spectroscopic imaging compared with conventional MR imaging. AJNR Am J Neuroradiol 24:1989-1998 